\title{
Prevalence of musculoskeletal injuries among adolescent squash players in the Western Cape
}

\author{
L Meyer (BSc Physio) \\ L van Niekerk (BSc Physio) \\ E Prinsloo (BSc Physio) \\ M Steenkamp (BSc Physio) \\ Q Louw (BSc, MASP, PhD)
}

Division of Physiotherapy, Stellenbosch University, W Cape

\begin{abstract}
Objective. To determine the prevalence of musculoskeletal injuries among adolescent squash players in the Western Cape.

Design. A retrospective descriptive survey was conducted during the first week of May 2006. Three schools were randomly selected from a list of the top 10 schools in the Western Cape high school squash league of 2005, with 106 squash players aged $13-18$ years participating in the study.

Setting. Injury data were collected for 106 players at three schools randomly selected from a list of the top 10 schools in the Western Cape high school squash league of 2005.

Interventions. An adapted structured self-administered questionnaire based on a previously validated musculoskeletal injury questionnaire was used to collect the data.

Main outcome measures. The main variables investigated were prevalence, mechanism and injury site of musculoskeletal squash injuries.

Results. Twenty-nine per cent of the players $(N=31)$ reported that they had sustained a squash injury in the 4 weeks prior to data collection. A total of 48 injuries were reported by the injured players. The most common injuries included those of the thigh (19\%), shoulder (13\%) and lower back (13\%). Forty-two per cent of players reported no specific mechanism of injury, but experienced pain
\end{abstract}

\section{CORRESPONDENCE:}

\section{Q Louw}

Department of Physiotherapy

Stellenbosch University

PO Box 19063

7505

Tel: 021-938 9300

Fax 021-931 1252

E-mail: qalouw@sun.ac.za not associated with a traumatic injury only while playing squash.

Conclusion. A relatively high prevalence of squash injuries was found. This preliminary study serves as a baseline for future research. Areas for further investigation were identified and this could lead to the implementation of preventive programmes and education to prevent injuries among adolescent squash players.

\section{Introduction}

Internationally, squash has been identified as a fast-growing sport. ${ }^{10}$ There are currently 15 million players worldwide from 135 participating nations. ${ }^{10}$ The ongoing increase in popularity has been associated with an increase in competitive levels in school leagues, at provincial level and even at national level. Young squash players are now participating at relatively more competitive levels of play compared with 20 years ago. ${ }^{10}$ This shift in focus among young people from enjoyment of physical activity to competitiveness is placing high demands on the musculoskeletal and physical systems. ${ }^{10}$

Squash-related musculoskeletal injuries can occur to the upper and lower limbs or back. ${ }^{11}$ The general injury prevalence among squash players is about $45 \%$. $^{3}$ A critical review of squash epidemiological studies indicated that squash players most commonly report acute soft-tissue injuries at hospital emergency departments. ${ }^{11}$ Lower-limb injuries account for the majority of the injuries sustained by squash players. ${ }^{11}$ The knee and ankle joint are reportedly the most commonly injured body regions in squash. ${ }^{11}$ The shoulder joint is the most frequently injured upper-limb region. ${ }^{3}$

Squash is a high-intensity sport that requires high-speed movements around the court while maintaining control over ball placement and being aware of the spatial orientation of the opponent. ${ }^{11}$ In order to hit the ball, squash players need large range of joint motion and velocity of limb action. ${ }^{11}$ Injury risk factors in squash include the physical demands of the sport, the speed, size and physical properties of the ball, court surfaces, the confined area of play and close proximity of players when swinging a racket. ${ }^{11}$ 
The maturing adolescent musculoskeletal system may increase the risk of musculoskeletal injury. ${ }^{5}$ Preadolescent and adolescent players have open growth plates, reduced muscle power, lower levels of co-ordination and smaller stature than adult players. ${ }^{5}$ Decreased soft-tissue flexibility is also evident in adolescents due to the inability of soft tissues to accommodate the rapid growth of skeletal structures such as the long bones of the femur. ${ }^{14}$ The biomechanical demands placed on the vulnerable neuro-musculoskeletal system of young people by high-intensity sports such as squash may be an injury risk factor. ${ }^{17}$

A search of the published literature indexed in electronic databases since 1995 revealed that squash injury literature has paid greatest attention to the problem of eye injuries. ${ }^{9,11}$ No published literature was found on the prevalence of squash injuries among adolescent players. The literature search of electronic databases also indicated that no epidemiological research into squash injuries has been published over the past 10 years. A manual search of the South African Journal of Sports Medicine since 1990 also yielded no reference to publications on squash injuries among South Africans. The aim of this study was therefore to ascertain the prevalence and types of injuries among high school squash players in the Western Cape.

\section{Methods}

\section{Study design}

A retrospective descriptive survey with a recall period of 4 weeks was conducted to ascertain the injuries that were most common amongst adolescent squash players in the Western Cape high school squash league.

The Western Cape Education Department granted permission to conduct the study. Ethical approval to conduct the study was obtained from Stellenbosch University. Players signed an informed consent form before participating in the study. The questionnaire was completed anonymously to ensure the anonymity of all the players.

\section{Subject selection}

The population comprised adolescent high school squash players in the Western Cape.

A list of the top 10 high schools in the Western Cape high school squash league of 2005 was obtained from the co-ordinator of the Western Cape provincial squash teams. Three schools were then randomly selected from the list of the top 10 schools, using a randomised table. After the three selected schools had verbally agreed to participate, an email was sent to the coach of each school outlining the project aims and the procedure of the study.

Epi-Info Statcalc Version 3.3 (Georgia, USA) was used to determine the sample size. Published reports on adolescent sport injury prevention ascertained that the injury prevalence was about $12 \% .^{18}$ It was determined that about 108 players were required, based on an expected injury prevalence of $12 \%$ and $80 \%$ statistical power.

The inclusion criteria of the study were: $(i)$ male and female squash players registered as participants in the high school squash league of 2006; (ii) adolescent squash players aged 13 - 18 years old; and (iii) players who had completed an informed consent form.

The exclusion criterion of the study was players who were absent on the day of data collection.

\section{Data collection}

The instrument used by the researchers for the purpose of the study was an adapted structured self-administered questionnaire based on a previously validated questionnaire used for adolescent basketball players in Cape Town. ${ }^{18}$

This study focused on the prevalence of squash injuries in adolescent players and not on the injury patterns found specifically in the knee, as in the study on basketball players conducted by Louw et al. ${ }^{18}$ Questionnaire information such as warm-up, level of play, and the number of hours played per week was regarded to be appropriate for this study.

The questionnaire was divided into two sections to collect general information and injury information data. Injury information consisted of all squash-related musculoskeletal injuries sustained during the 4 weeks prior to data collection as well as injuries sustained in any other structured sport before this period. The participants could report all body parts injured during the study period of 4 weeks in the table provided in the questionnaire. Players also reported on the hours played per week, warm-up, level of play and treatment received for sustained injuries (Table I).

The questionnaires were validated for face, content and construct validity. Two experienced researchers who had previously conducted similar epidemiological studies were consulted to evaluate the questionnaire content validity. The

\section{TABLE I. Summary of questionnaire content}

\begin{tabular}{ll}
\hline I. Personal information & Age, gender, handedness, starting age of playing squash \\
II. Frequency of play & Playing hours per week, number of days play per week \\
III. Warm-up & Activities during these sessions \\
IV. General injuries sustained & Reporting of any injury to a body part prior to the last month \\
V. Squash injuries & Injuries sustained during the last 4 weeks, mechanism of injury, body part injured \\
VI. Treatment received & Any type of treatment received, e.g. physiotherapy, rest, medication
\end{tabular}


consulted researchers were of the opinion that the content of the questionnaire was valid. The questionnaire was translated and back-translated from English into Afrikaans by professional translators.

To assess construct validity, the questionnaire was piloted among 20 high school squash players to assess whether they understood all the questions. The players experienced no problems in answering the questionnaire, and no changes were subsequently made to the questionnaire.

Data were collected retrospectively over a 4-week period and similar recall time frames have been employed in published reports of adolescent sports injuries. ${ }^{12}$

To determine reliability, player responses were verified by surveying the parents in a manner described by Grimmer et al. ${ }^{12}$ A sub-sample 10 questionnaires were selected randomly using a randomisation table. The parents of these players were telephoned after completion of the data collection to verify the responses of the young players. There was $100 \%$ agreement between the responses of parents and their children, indicating reliability of the player responses.

Permission was obtained from the selected schools, the Western Cape Education Department and coaches. The researchers visited two of the schools at the squash courts during practice and one at the end of the school day to collect the data. The data at all three schools were collected during the same week.

At each school the researchers explained the purpose of the study, emphasising that players should only report on squash injuries that had occurred in the 4 weeks prior to data collection. The researchers were present during the completion of the questionnaires to attend to any queries. Questionnaires took approximately 15 minutes to complete and were collected immediately to ensure a high response rate.

\section{Injury definition}

An injury was defined as one that occurred during practice or competition resulting from a traumatic incident. The definition also encompassed overuse injuries not initiated by a specific traumatic incident, but causing symptoms including pain or swelling while or after player squash. ${ }^{2}$

\section{Statistical analysis}

The data were analysed descriptively by calculating percentages of occurrences, and statistically by using the chi-square test for determining if potentially significant relationships existed between variables. Analyses were done using Statistica Version 7.1 (www.statsoft.com). Probability estimates (odds ratios (ORs)) were calculated to assess the effect of injury-related factors such as gender, not warming up, playing for a club and pre-existing injury. Significant risk was identified by $95 \%$ confidence limits around odds ratios where neither $95 \%$ confidence limits encompassed the value of 1 . Odds ratios were also calculated using Epi-Info Version 3.3 (Georgia, USA).

\section{Results}

\section{Sample description}

The sample consisted of 106 high school squash players. Boy and girl team players as well as the reserves were part of the sample if they were eligible to participate. Approximately $70 \%$ of the respondents were male and $30 \%$ female. The average age for females was $16.0 \pm 1.2$ years and the average age for males $16.0 \pm 1.3$ years (Table II). None of the players was absent on the day of data collection. Consent was obtained from all squash players.

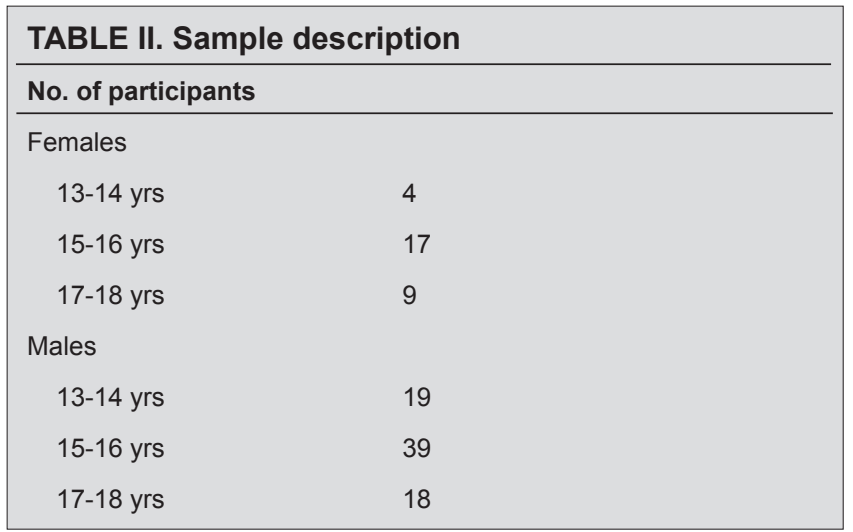

One hundred and nine questionnaires were completed by the players. Only 106 were usable due to incomplete information. None of the players were absent or did not provide informed consent on the day of data collection. About $51 \%$ of the players had started to play squash between the ages of 13 and 14 years.

\section{Squash injury prevalence}

Twenty-nine per cent of players $(N=31)$ reported that they had sustained a squash injury within the 4 weeks prior to data collection. A total of 48 injuries were reported by the injured players.

- Gender differences regarding injuries. Twenty-five per cent of squash injuries sustained in the 4 weeks prior to data collection were reported by females, while males accounted for $75 \%$ of the squash injuries. However the odds ratios indicated that males were not more likely to sustain more injuries than females (OR 0.79 , 95\% confidence interval (Cl): $0.31-2.2)$.

- Exposure and injury. On average, players practised twice a week for about 2 - 4 hours. The injury rate was calculated per 1000 playing hours of exposure. The total exposure was calculated by totalling the total exposure hours reported by the players. Considering that the 48 injuries were sustained by the 106 players, the injury rate per 1000 hours of exposure was about 0.45 per 1000 playing hours. 
- Injury among club and school players. Twenty-six per cent of the players played for a club while $14 \%$ played at provincial level. The results revealed a tendency for club players to sustain more injuries $(41 \%)$ than school players ( $25 \%$ injured). The odds ratios also indicated a tendency for club players to be more at risk of injury, as the lower confidence interval was only marginally insignificant (OR $0.9,95 \% \mathrm{Cl}: 0.91-5.9$ ).

- Pre-existing injuries. Most of the injuries (32\%) sustained prior to the 4-week recall were incurred while playing squash. Any history of previous injury before the 4-week retrospective data collection time frame could be reported. Other sports that also resulted in most of the injuries before the 4-week study period were rugby $(18 \%)$ and hockey $(14 \%)$, as indicated in Fig. 1.

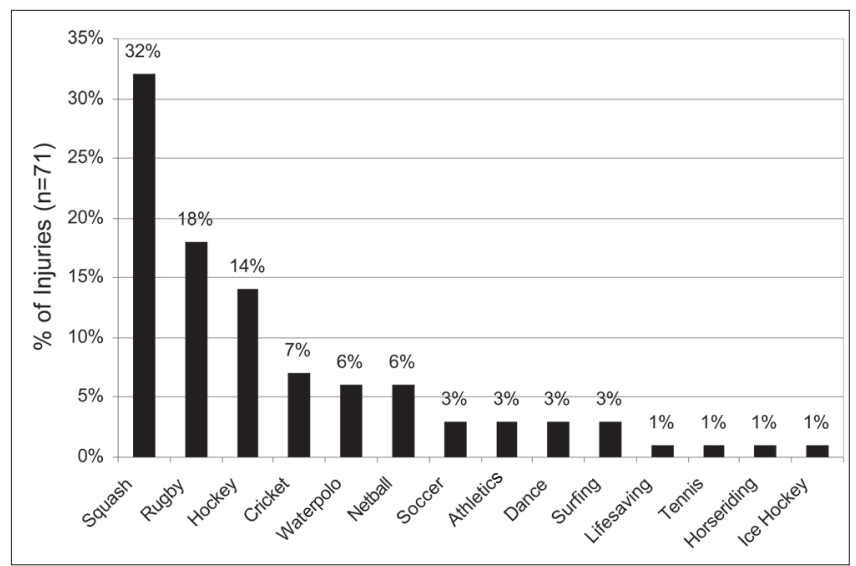

Fig. 1. Percentage of injuries sustained in sport prior to the 4-week study period.

There was also a tendency for players with pre-existing injuries to be more at risk for developing injuries while playing squash (OR 2.28, 95\% Cl: $0.92-6.2$ ) as the lower confidence interval was only marginally insignificant.

- Other sport participation. Eighty-nine per cent of the respondents also took part in other structured sports. More than half of the players (64\%) had sustained an injury while taking part in other sports before the start of the 4-week injury recall period of this study. It is notable that these injuries were not sustained within the 4 weeks prior to data collection. The most popular sports played by the study participants were hockey $(49 \%)$, rugby $(17 \%)$, water polo (9\%) and cricket (9\%).

- Injury location. Nineteen per cent of the 48 injuries reported by the participants involved the thigh musculature. The lower back and shoulder were also commonly injured while playing squash (13\%) (Fig. 2).

- Warm-up related to injury. Most of the players (93\%) warmed up before play. The players preferred stretching (77\%), game skills (52\%) and slow jogging (40\%). Forty three per cent of the players who did not warm up were injured compared with $27 \%$ of players who performed a warm-up prior to playing squash. The question did not spe-

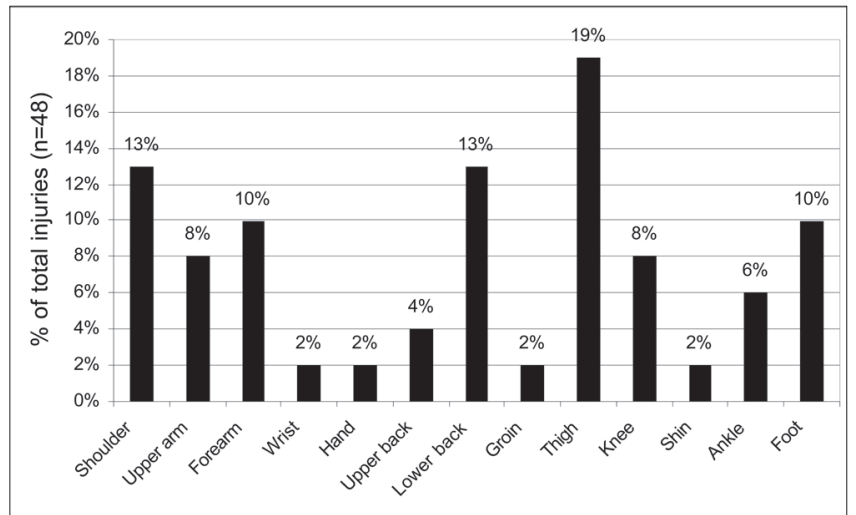

Fig. 2. Percentage of body locations injured while playing squash during the 4-week recall period.

cifically ask whether subjects warmed up before the actual session in which the injury was sustained. The question assessed whether the players generally performed a warmup before playing squash.

- Injury mechanism. A total of 42 injury mechanisms were reported by the players. The most common injury mechanism was 'pain without a traumatic incident' which may be indicative of overuse type of injuries (Fig. 3).

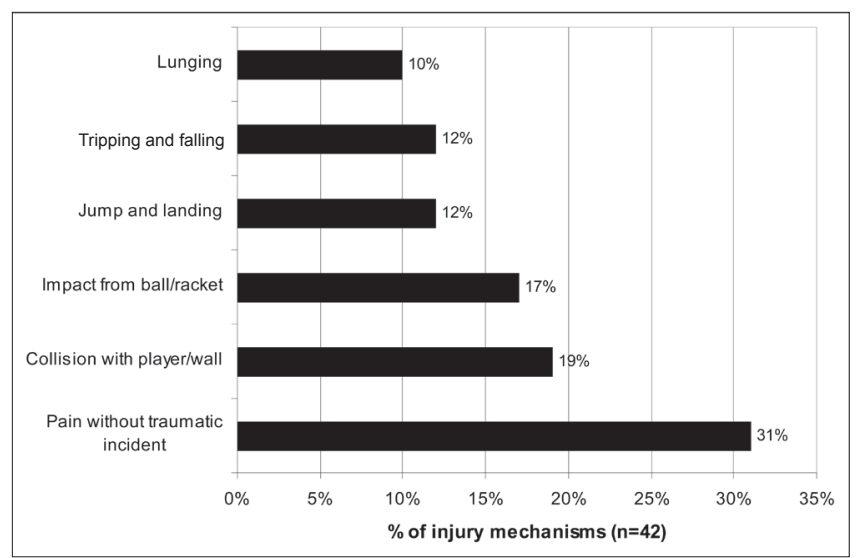

Fig. 3. Squash injury mechanisms.

- Injury management. Cold packs were the preferred choice of treatment (40\%) applied by the players for the squash injuries. Physiotherapy (35\%) and rest (35\%) were the other two types of treatments used most often by young squash players.

\section{Discussion}

This epidemiological retrospective survey was conducted to ascertain the prevalence and types of squash injuries among adolescents in the Western Cape. The researchers support the statement of Macfarlane and Shanks ${ }^{19}$ who report that only a small amount of musculoskeletal injury-related research has been done on squash players. However, the researchers found that in the relatively short study period of 4 weeks, almost one-third of the respondents reported a squash injury. In view of the short time available for the study, this indicates a relatively high prevalence of squash 
injuries and therefore further studies of injuries in adolescent squash players could be of high value.

The thigh was reportedly the most common site of injury. Injuries to the lower limb have been found to be the most common site of injury. ${ }^{11}$ The femur significantly increases in length during growth spurts and thigh muscles including the quadriceps muscle often cannot reach the flexibility required to accommodate for the increase in skeletal growth. ${ }^{14}$ This mismatch between bone length and muscle flexibility increases the risk of injury during challenging sporting manoeuvres that require balance and control. The high prevalence of thigh injuries among adolescent squash players signals that flexibility and neuromusculoskeletal training should be encouraged in an attempt to prevent injuries.

The lower back was found to be one of the common sites of injury (13\%) among these young adolescent players. This correlates with the research done by Macfarlane and Shanks, ${ }^{19}$ who found that squash played a significant role in the onset and exacerbation of back pain. Their study indicated that additional loading on the lumbosacral spine, which is caused by the combination of lower bending and rotation required in squash, may predispose players to back injuries. Injuries can lead to musculoskeletal changes and therefore be a large predisposing factor for future back problems. ${ }^{15}$ Back injuries sustained during childhood and adolescence are also one of the most common predictors of back pain experienced during adulthood. ${ }^{15}$ Chronic back pain in adults can have economic implications associated with the increased financial burden placed on society due to the greater need for health care. ${ }^{15}$ This early onset of back pain as well as the reduced muscle power, lower levels of co-ordination and imbalance between strength and flexibility in adolescents, ${ }^{1,5}$ emphasises the necessity for research, preventive programmes and treatment in this area.

The shoulder was also a common body region injured while playing squash (13\%). Squash involves repetitive overhead shoulder activity of the dominant arm in which the racquet is held. ${ }^{13}$ Strain is therefore placed on the neuromusculoskeletal structures around the dominant shoulder region and this could predispose the shoulder to overuse, instability and traumatic injuries. The research by Cullen and Silko ${ }^{8}$ found that most shoulder injuries are of traumatic origin, e.g. impact against a wall, also reported to be a common injury mechanism in this study.

The study findings indicate a definite tendency towards a higher injury rate if players did not warm up before play. Squash is a high-intensity sport with considerable physical stress and risk of contact ${ }^{6}$ and therefore sufficient warm-up is of the utmost importance. Warm-up prepares the body for exercise. ${ }^{4}$ Possible beneficial effects include increased blood flow to the muscles, increased speed of nerve impulses, increased range of motion and decreased stiffness of connective tissue leading to the decreased likelihood of tears. ${ }^{4}$ Inadequate warm-up is seen as a training error which could result in injury. A lack of understanding of the benefits of warm-up by the coaches and players, as well as insuf- ficient time management and effort from these two parties, could be possible reasons for the players not warming up.

Results showed that most players $(42 \%)$ had no specific traumatic injury, but just felt pain while or after playing squash. This finding indicates that overuse may play a role in musculoskeletal injuries among squash players. This finding is in agreement with published squash epidemiological studies which also report that overuse may be a common injury mechanism in squash. ${ }^{11,16}$ Strain on the musculoskeletal system resulting in microscopic injury can lead to pain or injury if the physiological threshold of body structures is exceeded. ${ }^{8}$ Strain placed on the musculoskeletal system of adolescent squash players, coupled with general soft-tissue inflexibility make young players vulnerable to injury. ${ }^{14}$

Level of play could also possibly add to the number of injuries sustained, since club players presented with more injuries. Club players usually spend more time on the squash courts and are therefore on an exposure basis alone more likely to suffer an injury. ${ }^{7,18}$ In addition, younger players are less experienced than adults and this may further impose greater injury risk. ${ }^{11}$ Less experienced younger players often play too close to their physical opponent, do not follow the path of the ball well and are not yet well trained in correct follow-through techniques. ${ }^{20}$ Inadequate coaching and supervision of younger players, e.g. regarding sufficient warm-up also further contributes to injury risk.

Two-thirds of the respondents received treatment for injuries sustained during the 4-week study period. The fact that no players reported any surgical intervention and that cold packs were most often used as treatment, could indicate that injuries were not very severe or that they were not adequately managed and could therefore recur. Research into the aetiology of squash injuries indicates that the most severe injuries involve the eye. ${ }^{11}$ Further research into the severity of squash injuries is necessary before any conclusions can be made concerning this.

\section{Conclusion}

The results of the study show a high prevalence of squash injuries among adolescent squash players in the Western Cape. Although no statistically significant results were found concerning associated factors predisposing players to such a high rate of injuries, some tendencies were identified. These include the role of warm-up and risks involved at a higher level of play, for instance among club members. Detailed analysis of individual exercise parameters (e.g. body mass index, height, fitness level), an extended study period, information on the severity of injury and the exact origin or cause of injury, were identified for possible future studies. This study provided the first set of preliminary data on musculoskeletal injuries among South African adolescent squash players and serves as a baseline for future research. Analysis of epidemiological injury data can assist in identifying putative risk factors which can be evaluated in the implementation of intervention programmes. 


\section{REFERENCES}

1. Baxter-Jones A, Maffulli N, Helms P. Low injury rates in elite athletes. Arch Dis Child 1993; 68:130-2.

2. Beachy G, Akau C, Martinson M, Olderr T. High school sports injuries. A longitudinal study at Punahou school: 1988-1996. Am J Sports Med 1997; 25: 675-81.

3. Berson BL, Rolnick AM, Ramos CG. An epidemiologic study of squash injuries. Am J Sports Med 1981; 9:103-6.

4. Brukner P, Khan K. Principles of injury prevention. In: Clinical Sports Medicine. 2nd ed. Sydney: McGraw Hill, 2001:84-126.

5. Bylak J, Hutchinson MR. Common sports injuries in young tennis players. Sports Med 1998; 26: 119-32.

6. Chard MD, Lachmann SM. Racquet sports - patterns of injury presenting to a sports injury clinic. Br J Sports Med 1987; 21:150-3.

7. Clavisi O, Finch C. Striking out squash injuries - what is the evidence? Injury Control and Safety Promotion 1999; 6:145-57.

8. Cullen PT, Silko GJ. Indoor racquet sports injuries. Am Fam Physician 1994; 50: 374-80.

9. Eime R, Finch $\mathrm{C}$. Have the attitudes of Australian squash players towards protective eyewear changed over the past decade? Br J Sports Med 2002; 36:442-5

10. Eime R, Zazryn T, Finch C. Epidemiology of squash injuries requiring hospital treatment. Inj Control Saf Promot 2003; 10:243-5.
11. Finch C, Eime R. The epidemiology of squash injuries. Int J Sports Med $2001 ; 2: 1-11$

12. Grimmer K, Williams J, Pitt M. Reliability of adolescent self report of recent recreational injury. J Adolesc Health 2000; 27: 273-5.

13. Gross GW. Imaging. In: Stanitski CL, DeLee JC, Drez D, eds. Pediatric and Adolescent Sports Medicine. Philadelphia: WB Saunders, 1994.

14. Gurewitsch AD, O'Neill MA. Flexibility of healthy children. Archiv fur Physikalische Therapie 1944; 25: 216-21.

15. Hestbaek L, Leboeuf-Yde C, Kyvik KO. Is comorbidity in adolescence a predictive for adult low back pain? A prospective study of a young population. Biomedical Central Musculoskeletal Disorders 2006; 7:29.

16. Jones D, Louw Q, Grimmer K. Recreational and sporting injury to the adolescent knee and ankle: Prevalence and causes. Aust J Physiother 2000; 46: 179-88.

17. Kibler WB, Safran MR. Musculoskeletal injuries in the young tennis player Clin Sports Med 2000; 19:784-92.

18. Louw QL, Grimmer K, Vaughan K. Knee injury patterns among young basketball players in Cape Town. South African Journal of Sports Medicine 2003; 15:9-15.

19. Macfarlane DJ, Shanks A. Back injuries in competitive squash players. $J$ Sports Med Phys Fitness 1998; 38:337-43.

20. Soderstrom C, Doxanas M. Racquetball. A game with preventable injuries. Am J Sports Med 1982:10:180-3.

\section{Sports Medicine, An Issue of Physical Medicine and Rehabilitation Clinics}
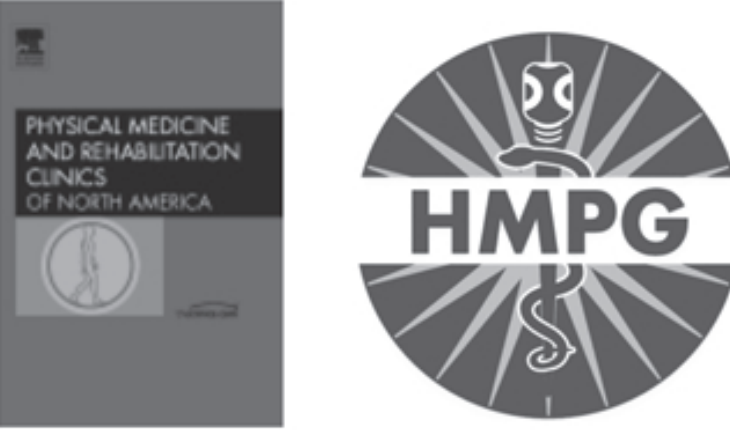

To Order Please Contact:

Health \& Medical Publishing Group

Private Bag X1, Pinelands, 7430

Tel: 021 - 6578200 - Fax: 021- 6834509

e-mail: carmena@hmpg.co.za /

brents@hmpg.co.za

By Gregory A. Strock, MD; and Ralph M. Buschbacher, MD, Clinical Associate Professor and Interim Chair, Department of Physical Medicine and Rehabilitation, Indiana University; Indiana University Medical Center; Residency Program Director, Community Hospitals of Indiana, Indianapolis, IN, USA

\section{ISBN $1416039287 \cdot$ Hardback $\cdot 240$ Pages}

\section{Saunders . Published October 2006}

Treating an elite athlete or a weekend player has its challenges mainly to get them back in the game right away. This issue covers injuries and treatments for an assortment of sports: golf, running, triathalon, basketball and more. Also included are two exciting chapters on sports psychology and performance enhancing drugs and chapters on altitude medicine and martial arts. 